\title{
Screening of Selected Sorghum Genotypes for Resistance to Covered Kernel Smut Disease in Western Kenya
}

\author{
Okongo Caroline ${ }^{1}$, Ouma Evans ${ }^{2} \&$ Gudu Samuel $^{3}$ \\ ${ }^{1}$ School of Agriculture, Natural Resources and Environmental Studies, Rongo University, Rongo, Kenya \\ Correspondence: Caroline Auma Okongo, School of Agriculture, Natural Resources and Environmental Studies, \\ P.O. Box 103-40404, Rongo, Kenya. Tel: 254-721-964-016. E-mail: carohokongo@yahoo.com
}

Received: March 4, 2021

Accepted: May 2, $2021 \quad$ Online Published: June 15, 2021

doi:10.5539/jas.v13n7p63

URL: https://doi.org/10.5539/jas.v13n7p63

\begin{abstract}
Sorghum is an important food security crop for arid and semi-arid tropics but its production is hampered by many biotic and abiotic factors including covered kernel smut disease (CKSD) caused by fungus Sporosorium sorghi in the Ustilaginaceae family. The disease attacks susceptible sorghum genotypes causing yield losses estimated at $43 \%$ in Western Kenya. This study determined the response of selected sorghum genotypes to CKSD under field and greenhouse conditions. A total of 15 elite sorghum genotypes were screened under field conditions in Migori and Homa Bay sites and under greenhouse at the University of Eldoret. Data on disease incidence and severity were collected per genotype and analyzed using R-Studio software and means were separated at $1 \%$ using Tukey's test. Results showed significant differences among genotypes for disease incidence and severity under fields and greenhouse conditions. Disease incidence varied significantly $(\mathrm{p}<0.001)$ among the genotypes ranging from zero (for T53, T30, IS3092, N4 and N68) to 64\% (for Nyadundo2) under field conditions but ranged from $0-69 \%$ under greenhouse conditions. Similarly, severity followed the same trend with C26 having the worst attack with a score of 5 while T53 recorded the least (score of 1). This study has identified potential sources of resistance for covered kernel smut disease that can be utilized to manage the disease and significantly improve sorghum yields in the target regions.
\end{abstract}

Keywords: sorghum, covered kernel smut, incidence, severity

\section{Introduction}

Sorghum (Sorghum bicolor (L.) Moench) is ranked fifth in importance among cereals in the world and is a major food crop for developing countries (FAO, 2012). It is particularly important in areas with high temperatures and low rainfall due to its resilience (Hayden, 2002). The sorghum grains can be used for syrup production, making of leavened and unleavened bread, bio-energy, bio-ethanol production and preparation of alcoholic beverages (Tonapi et al., 2020). In Sub-Saharan Africa, Middle East, North Africa and India sorghum is mainly used as human food while in Europe, Australia, China, and Western Hemisphere countries it is used as animal feed, forage, and for industrial purposes including ethanol production. Sorghum production is mainly concentrated in Asia, Sub-Saharan Africa and the Americas and Caribbean (FAO, 2012).

Its global consumption is estimated to be 61.0 million metric tons per year (USDA, 2019). However, grain yield in most parts of the world is relatively low, estimated at $0.925 \mathrm{t} / \mathrm{ha}$ compared to $5 \mathrm{t} / \mathrm{ha}$ reported from experimental stations (ICRISAT, 2004). The low yield is attributed to a number of factors including biotic, abiotic and socio-economic factors (Esele, 2013). The most important diseases and pests of sorghum include shoot fly, stem borer, shoot bug, aphids, sorghum midge, head bug and covered kernel smut disease. Collectively, these constraints limit sorghum production and hamper its productivity across regions of the world (Tonapi et al., 2020).

Covered kernel smut disease (CKSD) caused by Sporisorium sorghi in the Ustilaginaceae family is a major constraint in sorghum production (Mtisi \& McLaren, 2008). The fungus is seed-borne and develops systemically as the sorghum crop grows. In Kenya, its incidence is exacerbated by the informal sorghum seeds system whereby small-scale farmers continue to share and exchange retained own untreated seeds for planting the next season's crop among the communities (Gwary et al., 2007). According to Howard et al. (2005) maturing fruiting bodies of the fungus called sori rupture and release teliospores that infects seeds on the same or other sorghum plants. The teliospores of the fungus replace the grain in the panicle causing direct crop losses in grains. 
According to Sisay et al. (2012) the fungus Sporisorium sorghi in the Ustilaginaceae family can grow and develop at $10-32{ }^{\circ} \mathrm{C}$, but the optimum soil temperature conducive for the disease development is $18-25^{\circ} \mathrm{C}$. The infection is established in warmer and wet soils with humidity of between $15-20 \%$. More importantly, periods of delayed seed germination and emergence are optimal for the infection (Ashok et al., 2011) which enhances its incidence. In the year 2012, Gautam et al., recorded more than 50\% disease incidence in Ethiopia. In general disease incidence varies from place to place. Annual yield losses due to CKSD in Africa reaches 10\% with localized losses of $60 \%$ or more (Sisay et al., 2012). In Kenya, CKSD also causes significant yield losses ranging from 42-48\% (Okongo et al., 2019). However, in Migori and Homa Bay Counties, little is known about its incidence, severity and distribution. Some new improved sorghum varieties that were introduced in the area by the Rongo University Sorghum Improvement Team in 2017 were infected by the disease (http://www.ccrp.org) raising the issue of its management.

To minimize yield losses due to CKSD, several methods can be used such as chemicals, cultural, biological and through breeding for tolerant crop varieties. Chemical method includes the use of fungicides such as Captan and Carboxin+Thiram (Vitavax) which assist in reducing the incidence and severity of the disease on sorghum but does not completely control the disease (Jere, 2004). Moreover, most of these fungicides are extremely expensive and unaffordable to the smallholder farmers.

Several cultural methods are available for controlling the disease including soaking of seeds in water for four hours followed by drying of seeds under shade, collection of smutted ear heads and incinerating them (IPM, 2008). According to Adane and Gatam (2000), CKSD can also be controlled by use of fermented cattle urine and botanicals from Abeyi (orm) Maesa lanceolata. However, the two methods are not widely used and their efficiency in different regions need to be established. Moreover, Abeyi plant is not readily available for farmers in Western Kenya (Okongo et al., 2019).Therefore the CKSD remains a major threat to food security in western region despite the chemical, biological and cultural methods currently in use owing to their labour intensive nature and or cost.

The use of resistant genotypes is one of the most viable strategies for the control of covered kernel smut disease (Kutama et al., 2013). This is because orphan crops like sorghum has a low return to investment and therefore, the introduction of resistant varieties remains the most cost-effective and sustainable option to control covered kernel smut disease (Wilson, 2011). In Kenya, there is lack of smut resistant genotypes, creating a need to identify stable sources of resistance through screening which could be utilized directly or used in breeding programs to develop other resistant varieties. Therefore, this study seeks to improve production of sorghum through screening and selecting resistant genotypes to be used for management of covered kernel smut disease.

\section{Materials and Methods}

\subsection{Plant Materials}

A total of 15 plant materials were used which included the newly released sorghum varieties by Rongo University Sorghum Breeding Program, commercial variety and farmers' cultivars (Table 1) collected through field survey by Okongo et al. (2019).

Table 1. Sorghum genotypes used in the study

\begin{tabular}{lll}
\hline Plant Material & Source & Colour \\
\hline NYADUNDO 1 & Rongo University & Red \\
NYADUNDO 2 & Rongo University & Red \\
C26 & Rongo University & Cream \\
MUK27 & Makerere University & Brown \\
MUK60 & Rongo University & Red \\
T53B & Rongo University & Brown \\
N68 & Rongo University & Brown \\
T30B & Rongo University & Brown \\
E117B & Rongo University & Brown \\
MUK154 & Makerere University & Red \\
IS3092 & Kalro Katumani & Brown \\
N4 & Rongo University & Red \\
JOWI & Farmer & Red \\
OCHUTI & Farmer & Red \\
SEREDO & Kenya Seed Company & Brown \\
\hline
\end{tabular}




\subsection{Description of Experimental Sites}

The study was conducted in two counties, Homa Bay and Migori. The first site is located at $0^{\circ} 42^{\prime} \mathrm{S}$ and $34^{\circ} 50^{\prime} \mathrm{E}$, $1221 \mathrm{~m}$ above sea level, has an average annual temperature of $21.2{ }^{\circ} \mathrm{C}$ with a humidity of between $20-28 \%$ and annual precipitation of $1369 \mathrm{~mm}$ per year with Vertisol soil type.

Migori site is located at $1^{\circ} 07^{\prime} \mathrm{S}$ and $34^{\circ} 42^{\prime} \mathrm{E}$. It has an elevation of $1281 \mathrm{~m}$ above sea level with daily temperature ranging between $26-34{ }^{\circ} \mathrm{C}$ with humidity of between $18-20 \%$ and average annual rainfall estimated at $1100 \mathrm{~mm}$ with granite type of soil.

The greenhouse screening was done at the University of Eldoret located at $0.52^{\circ} \mathrm{N}$ and $35.27^{\circ} \mathrm{E}$ which has an elevation of $2090 \mathrm{~m}$ above sea level, average temperature of $15.8^{\circ} \mathrm{C}$ and average rainfall of $1263 \mathrm{~mm}$.

\subsection{Experimental Design and Procedures}

\subsubsection{Preparation of Sporidial Inoculum Suspension}

The CKSD inoculum was prepared by collecting 5 grams of dry teliospores from mature panicle smut infected sorghum genotypes from on-farm trials by shaking them out of the heads and sieving to remove the debris, The teliospores were then washed in $70 \%$ ethanol to sterilize then suspended on $250 \mathrm{ml}$ sterile water and plated on Potato Dextrose Agar (PDA) and incubated in the dark at $28{ }^{\circ} \mathrm{C}$ for 3 days. The sporidial colonies were then transferred in flask containing $100 \mathrm{ml}$ potato Dextrose Broth (PDB) and incubated on a rotary shaker for 4 days. The suspension was then filtered using a cheese cloth, which was then used to inoculate the seedlings with a hypodermic syringe according to procedures described by Frederiksen (2000).

\subsubsection{Germination of Sorghum Seeds in Pots}

Ten seeds of each of the fifteen sorghum genotypes (Table 1) were planted and grown in pots arranged in a Completely Randomized Design (CRD) replicated three times in the greenhouse, each pot was filled with $1.5 \mathrm{~kg}$ forest soil $+0.15 \mathrm{~g}$ teliospores and mixed with a handful of organic matter. The seedlings were then thinned when they were I month old to three seedlings per pot.

\subsubsection{Inoculation of Seedlings}

The inoculum suspension was then used to inoculate the seedlings with the help of a hypodermic syringe when they were $10 \mathrm{~cm}$ in height (4 weeks old). An inoculum suspension was injected into each seedling continuously until drops of the inoculum were seen at the top of the leaf.

For field screening, fifteen genotypes (described in Table 1) were planted in CKSD hotspots in Migori and Homa Bay sites. The experiments were set up in a Randomized Complete Block Design (RCBD) with three replications. Each genotype was planted in a $(2.25 \times 4) \mathrm{m}$ plot with 4 rows at a spacing of $(75 \times 20) \mathrm{cm}$. Standard agronomic practices were followed to raise a healthy crop.

\subsection{Data Collection and Statistical Analysis}

\subsubsection{Covered Kernel Smut Disease Incidence}

This was assessed on infected panicles by determining the proportion of sorghum plants showing the symptoms of the covered kernel smut disease compared to the total number of plants in the plot, and the incidence expressed as a percentage as described by Chaube and Punder (2005) using the formula:

$$
\text { Disease incidence per variety }=\frac{\text { Total number of diseased plants in the plot }}{\text { Total number of plants in the plot }} \times 100
$$

\subsubsection{Covered Kernel Smut Disease Severity}

Covered kernel smut disease severity was scored on the infected plants using disease resistance classification scale described by Gwary et al. (2001) and Marley et al. (2002) on a scale of 1-5 where 1 is immune showing no disease symptoms on the panicle, 2 is resistant showing $1 \%$ panicle area infected, 3 is moderately susceptible showing $2-10 \%$ head area attacked, 4 is susceptible with $11-25 \%$ head area covered with smut and 5 more than $26 \%$ with severe head damage as follows: 
Table 2. Disease resistance classification scale

\begin{tabular}{lll}
\hline Severity resistance rating & \% Panicle area infected & Description \\
\hline 1 & 0 & Immune \\
2 & 1 & Resistant \\
3 & $2-10$ & Moderately susceptible \\
4 & $11-25$ & Susceptible \\
5 & $>26$ & Very susceptible \\
\hline
\end{tabular}

Data collected on disease severity and incidence was transformed using square root transformation method and analyzed using R-Studio. Analysis of variance was done for the two sites and the greenhouse according to K. Gomez and A. Gomez (1984). Differences were accepted as significant at $\mathrm{p}<0.001$ and the means separated at $1 \%$ using Tukey`s range test.

\section{Results}

\subsection{Disease Incidence Under Field Conditions}

At Migori site, there were significant differences $(\mathrm{p}<0.001)$ on the incidence of covered kernel smut disease amongst the fifteen sorghum genotypes(Figure 1, Table 3) but replication and residuals had no effect on disease incidence, Four varieties namely N4, MUK24, N68 and IS3092 showed significant variation in disease incidence compared to the rest of the varieties. C26 had the highest mean disease incidence (60\%) compared to N68 (3\%) while the local checks (Ochuti and Jowi), Nyadundo1 and Nyadundo2 showed statistically similar disease incidence.

At Homa Bay site, there were significant differences $(p<0.001)$ on incidence of covered kernel smut disease amongst the fifteen sorghum genotypes (Figure 2, Table 3). Replication and residuals had no effect on disease incidence levels. Ochuti and Jowi, the local checks had the highest mean incidence of $56.7 \%$ while IS3092 had the lowest mean incidence of 3\% (Figure 1b). Nyadundo2 and Nyadundo1 had a mean incidence of $<50 \%$ which compared well with the commercial checks, Seredo which showed a mean incidence of $43.3 \%$.

Table 3. Mean square for covered kernel smut disease incidence for sorghum genotypes tested in Migori and Homabay sites

\begin{tabular}{llll}
\hline \multirow{2}{*}{ SOV } & \multirow{2}{*}{ DF } & \multicolumn{2}{c}{ Mean Squares } \\
\cline { 3 - 4 } & & Migori & Homabay \\
\hline REP & 2 & 73.16 & 13.89 \\
Genotype & 14 & $1936.2 * * *$ & $1690.02 * * *$ \\
Residual & 28 & 50.56 & 47.65 \\
\hline CV & & 9.2 & 4.3 \\
SED & & 5.8 & 5.64 \\
LDS & & 11.89 & 11.55 \\
\hline
\end{tabular}

Note. SOV: source of variation; DF: degree of freedom; SED: standard error deviation; LSD: least significance difference; $\mathrm{CV}$ : coefficient of variation. 


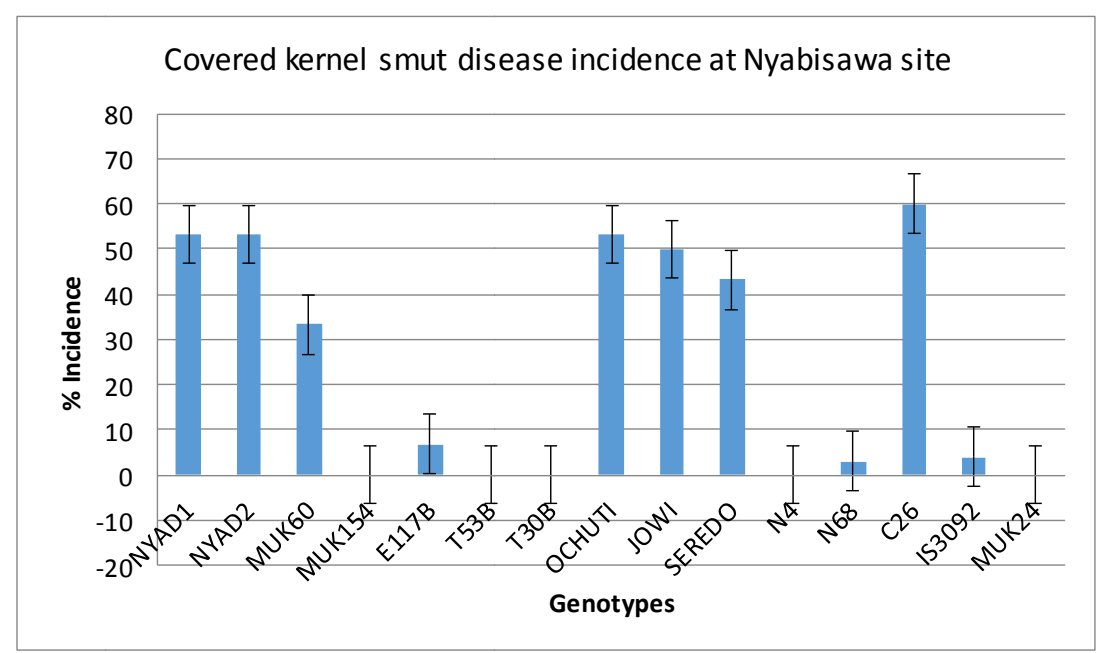

Figure 1. Covered kernel smut disease incidence at Migori site

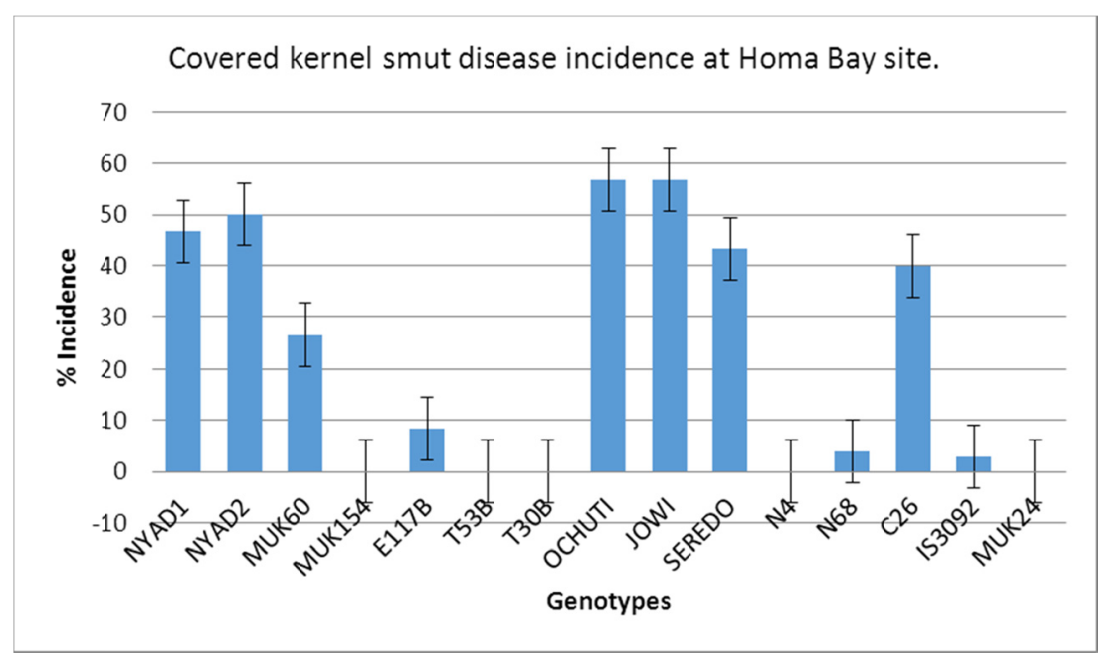

Figure 2. Covered kernel smut disease incidence at Homa Bay site

\subsection{Disease Incidence Under Greenhouse Conditions}

There were significant differences $(p>0.001)$ on the incidence of covered kernel smut disease amongst the fifteen sorghum genotypes screened (Figure 3, Table 4) C26 and Nyadundo 2 had the highest mean disease incidence (63.3\%) which was statistically different from that of IS3092 and MUK154 (3\%). Ochuti and Jowi the local checks showed statistically similar means of disease incidence level. 


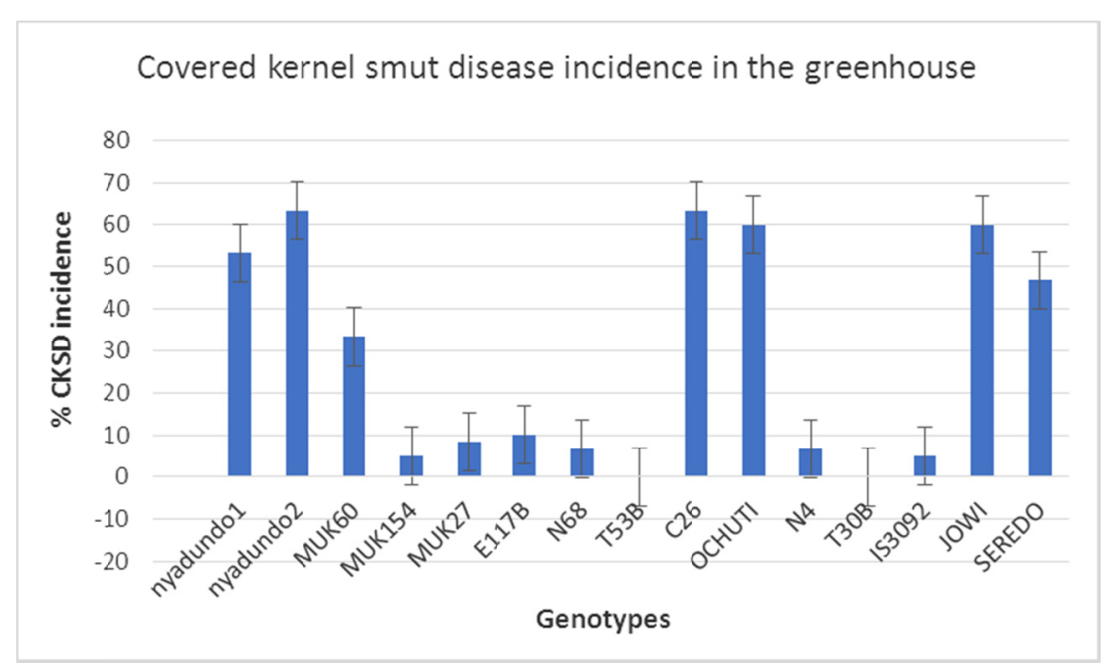

Figure 3. Covered kernel smut disease incidence in the greenhouse

Table 4. ANOVA table for covered kernel smut disease incidence in the greenhouse

\begin{tabular}{lllll}
\hline SOV & DF & Sum of Squares & Mean Square & F Value \\
\hline Genotype & 14 & 29431.1 & 2102.2 & $64.14^{* * *}$ \\
Residual & 30 & 983.38 & 50.56 & \\
Total & 44 & 33414.4 & & \\
\hdashline SED & $\mathbf{4 . 6 8}$ & & & \\
LSD & $\mathbf{9 . 5 5}$ & & & \\
CV & $\mathbf{7 . 3}$ & & & \\
\hline
\end{tabular}

Note. SOV: source of variation; DF: degree of freedom; SED: standard error deviation; LSD: least significance difference; $\mathrm{CV}$ : coefficient of variation.

\subsection{Severity Score of Covered Kernel Smut Disease on Sorghum Genotypes Under Field Conditions}

The differences on the severity of covered kernel smut disease were significant $(\mathrm{p}>0.001)$ among the fifteen sorghum genotypes tested (Table 5). Five varieties MUK154, MUK27, T53B, N4 and T30B recorded the lowest disease damage rating of 1 and were considered immune to covered kernel smut disease (Figure 5).

Genotypes E117, N68 and IS3092 had a score of 2 and were regarded as very resistant. C26 on the other hand had the highest mean severity score of 5 , and therefore was recorded as very susceptible. Nyadundo1, Jowi, Ochuti, Nyadundo 2 and Seredo had a score of 4 and therefore were considered susceptible.

At HomaBay site, the differences on the severity of covered kernel smut disease were significant $(p<0.001)$ among the fifteen sorghum genotypes tested. MUK154, MUK27, T53B, N4 and T30B did not show significant variation in terms of disease severity and recorded the lowest score of 1 . Therefore, these genotypes were considered immune to covered kernel smut disease. Another set of genotypes consisting of E117B, N68 and IS3092 had a disease severity score of 2 and hence were considered as very resistant. Amongst all the genotypes, the local checks, ochuti and jowi had the highest severity score of 4.7 and were classified as susceptible to the disease. 
Table 5. Mean square table for sorghum genotypes tested for covered kernel smut disease severity in Migori and Homabay sites

\begin{tabular}{llll}
\hline \multirow{2}{*}{ SOV } & \multirow{2}{*}{ DF } & \multicolumn{2}{c}{ Meansquares } \\
\cline { 3 - 4 } & & Migori & Homabay \\
\hline REP & 2 & 0.0889 & 0.0222 \\
Genotype & 14 & $7.327^{* * *}$ & $6.422^{* * *}$ \\
Residual & 28 & 0.1603 & 0.1651 \\
\hline CV & & 2.8 & 1.5 \\
SED & & 0.32 & 0.332 \\
LDS & & 0.66 & 0.679 \\
\hline
\end{tabular}

Note. SOV: source of variation; DF: degree of freedom; SED: standard error deviation; LSD: least significance difference; $\mathrm{CV}$ : coefficient of variation.

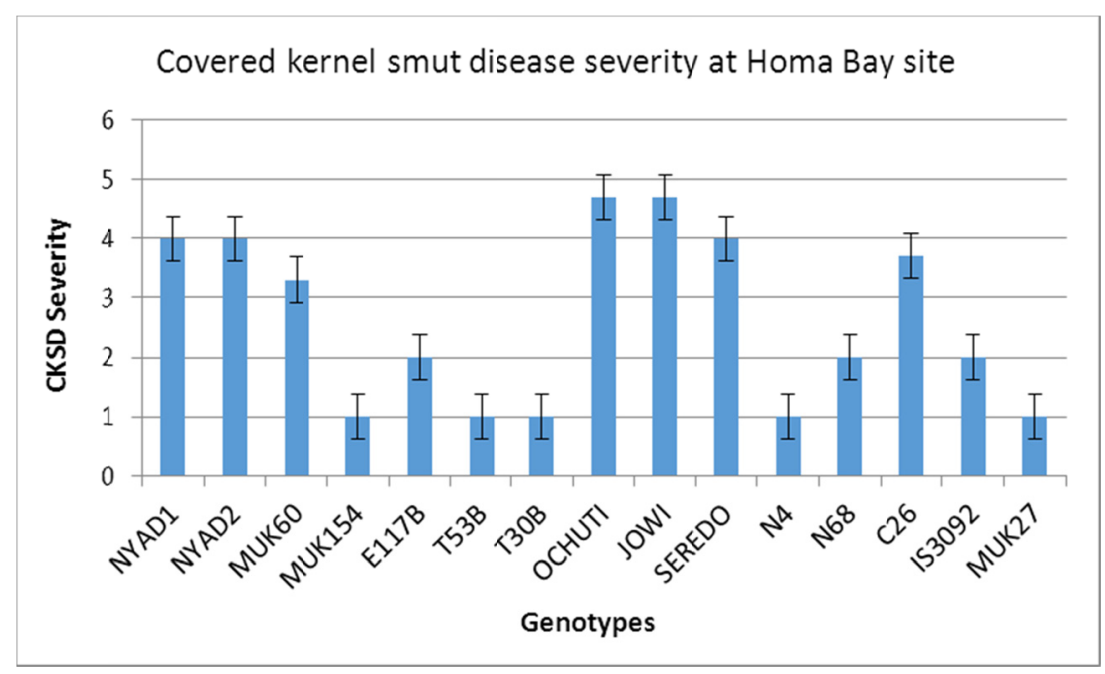

Figure 4. Covered kernel smut disease severity at Homa Bay site

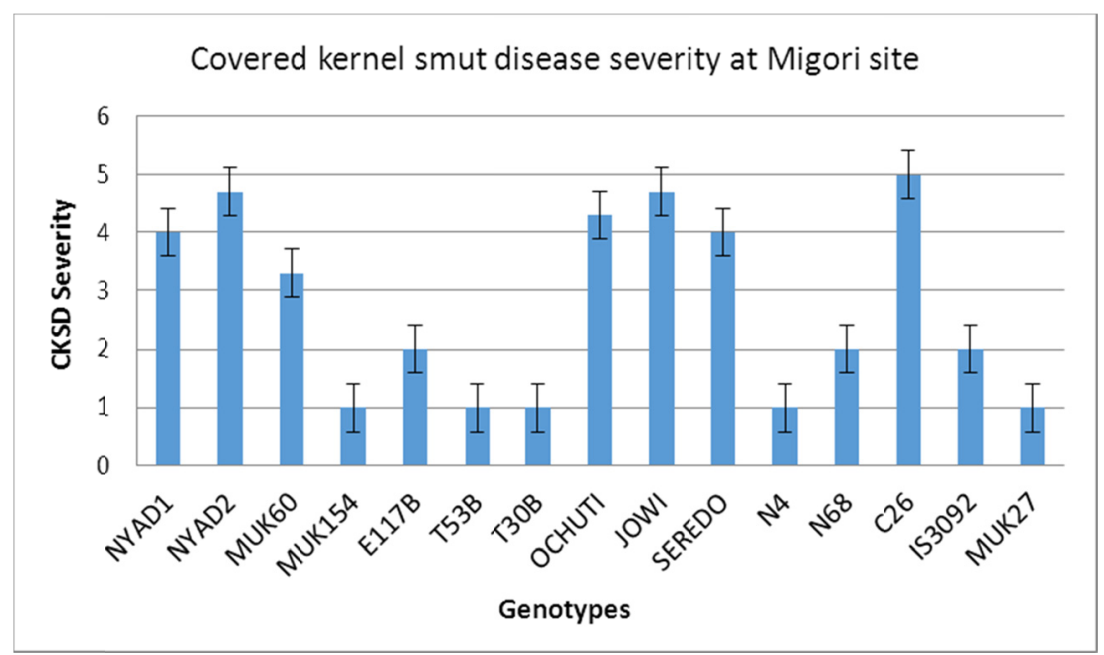

Figure 5. Covered kernel smut disease severity at Migori site

\subsection{Severity Score of Covered Kernel Smut Disease on Sorghum Genotypes Under Green House Conditions}

Under controlled conditions, the differences on the severity of covered kernel smut disease were significant $(\mathrm{p}<$ 0.001) among the fifteen sorghum genotypes tested (Table 5). MUK154, T53B, N4 and T30B were not 
statistically different $(\mathrm{p}<0.001)$ with regard to CKSD to the disease damage and obtained the lowest score of 1 (Figure 6) and were classified as immune to CKSD. Genotypes E117, N68 and IS3092 had a score of 2 and were classified as very resistant. Nyadundo1 and Seredo had a score of 4 and were considered as susceptible while C26, Ochuti, Jowi and Nyadundo2 on the other hand had the highest mean severity score of 5 and were considered as very susceptible.

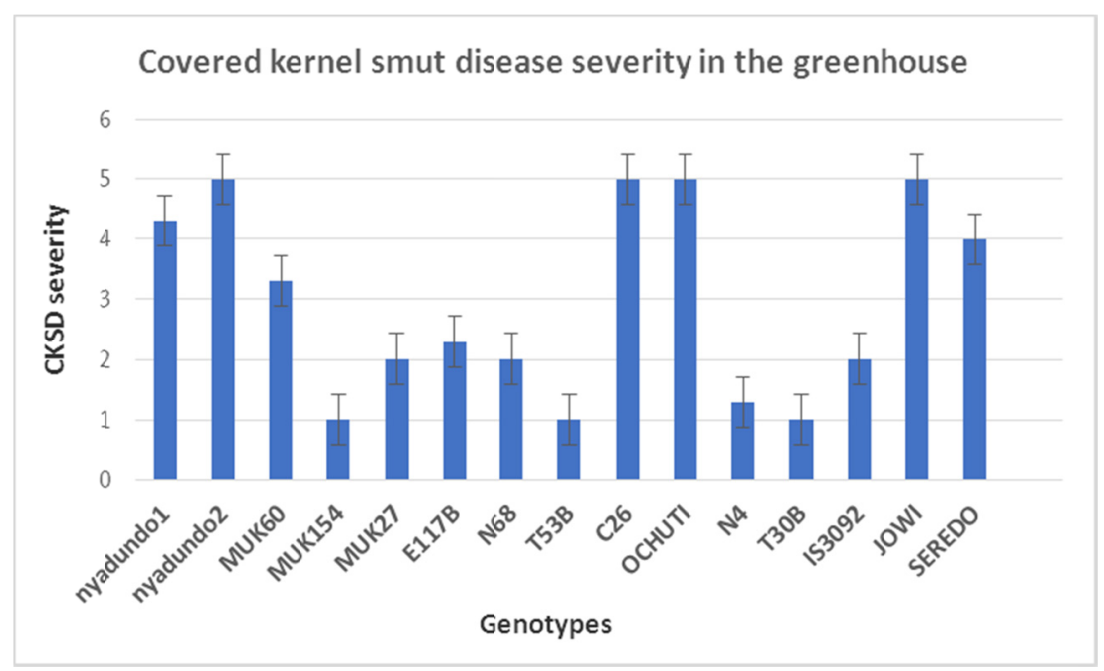

Figure 6. Covered kernel smut disease severity in the greenhouse

Table 6. ANOVA table for covered kernel smut disease severity in the greenhouse

\begin{tabular}{lllll}
\hline SOV & DF & Sum of Squares & Mean Square & F Value \\
\hline Genotype & 14 & 111.244 & 7.9460 & $57.08^{* * *}$ \\
Residual & 30 & 4.667 & 0.1556 & \\
Total & 44 & 115.91 & & \\
\hdashline SED & $\mathbf{0 . 3 2 2 0}$ & & & \\
LSD & $\mathbf{0 . 6 5 7 7}$ & & & \\
CV & $\mathbf{1 3 . 3}$ & & & \\
\hline
\end{tabular}

Note. SOV: source of variation; DF: degree of freedom; SED: standard error deviation; LSD: least significance difference; $\mathrm{CV}$ : coefficient of variation.

Table 7. ANOVA table for genotypes, sites and interaction

\begin{tabular}{lllll}
\hline SOV & DF & Sum of squares & Mean square & F Value \\
\hline Site & 1 & 4.2008 & 4.2008 & $13.4391^{* *}$ \\
Genotype & 14 & 11.4126 & 0.8152 & $2.607^{*}$ \\
G $\times$ E & 14 & 4.3761 & 0.3126 & \\
Residual & 14 & 4.3761 & 0.3126 & \\
\hdashline SED & $\mathbf{0 . 1 6 3}$ & & & \\
LSD & $\mathbf{0 . 8 3 0}$ & & & \\
CV & $\mathbf{0 . 5 5 9}$ & & & \\
\hline
\end{tabular}

Note. SOV: source of variation; DF: degree of freedom; SED: standard error deviation; LSD: least significance difference; $\mathrm{CV}$ : coefficient of variation.

There were significant differences $(\mathrm{p}<0.01)$ on the incidence of covered kernel smut disease amongst the fifteen sorghum genotypes, while sites were significantly different at $\mathrm{p}<0.001$ but $\mathrm{G} \times \mathrm{E}$ interaction and residuals had no effect on disease incidence (Table 7). 


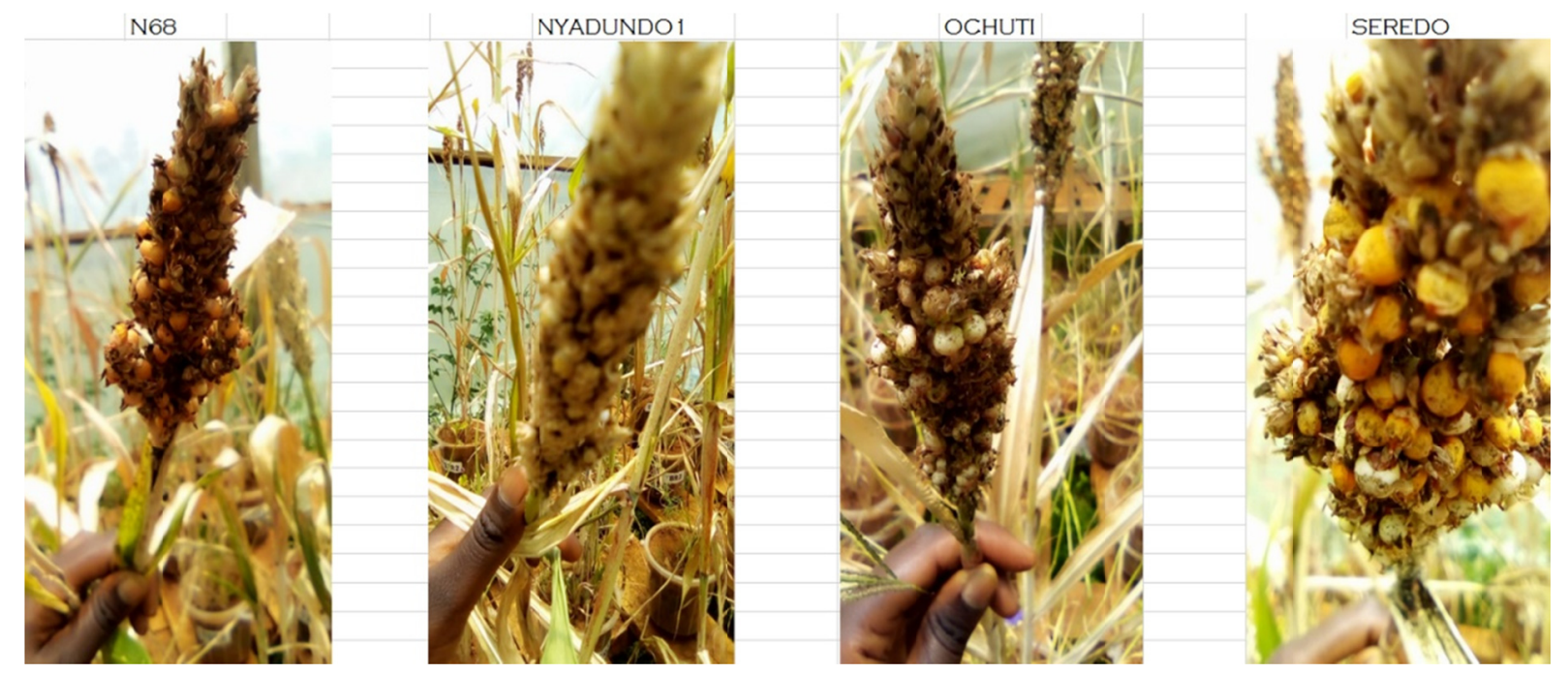

Figure 7. Different sorghum genotypes responding to covered kernel smut disease attack under greenhouse conditions

\section{Discussions}

\subsection{Variation in Disease Incidence Under Field and Glasshouse Conditions}

In this study, there were significant variation in disease incidence among genotypes and enviroments ranging from $0-64 \%$ at Homa Bay, Migori and in the greenhouse. The presence of highly significant differences between the two test sites for all the fifteen genotypes indicated that the genotypes performed differently across the test environments. There was no significant difference on $G \times E$ interaction therefore no emphasis on evaluating the sorghum genotypes across the environments.

The higher disease prevalence in some genotypes in Migori compared to HomaBay or greenhouse cannot be readily explained at the moment but could be due to different enviromental factors at the three sites such as soil type, temperature, moisture or variation in pathogen isolates. Previous research have attributed site to site incidence differences to the pathogens biology and enviromental factors that affect germination of teliospores (Gwary et al., 2007). Similar trends in disease incidence was also reported by Sisay e al. (2005) who emphasized that CKSD thrives better in enviroments with tempratures between $18-25{ }^{\circ} \mathrm{C}$ and a relative humidity of $15-20 \%$ which is similar to the conditions in which we did this experiment.

The inherent genetic differences among genotypes could be the second reason for observed variation in disease incidence observed that the host species specificity to the pathogen vary according to different genotypes of sorghum. Similarly Gwary et al. (2007) attributed the variations in disease incidence to the inherent genetic differences among individuals.

\subsection{Severity Score of Covered Kernel Smut Disease on Sorghum Genotypes Under Field and Greenhouse Conditions}

Significant variations in disease severity were observed in the fifteen genotypes in the current study. Phenotypically, the varieties were categorised as immune (MUK154, T53B, T30B, N4 and MUK24), very resistant varieties (E117B, N68 and IS3092), susceptibles (Seredo, Nyadundo1 and Nyadundo 2) and Ochuti and Jowi, very susceptible as described by Marley et al. (2002) depending on the degree of damage. Resistance to CKSD is also dependent on genetic difference among genotypes and enviromental conditions. This result also agreed with the early report by Nzioki et al. (2000) that most studies for resistance to sorghum covered kernel smut disease is controlled by single gene and therefore, weather resistant or susceptible a variety is will depend on the parent used.

In general the response of the genotypes to the disease followed a similar trend both under the two fields and green house conditions indicating that all conditions were conducive for detecting the occurrence of the diseases. However the disease severity in the greenhouse was higher compared to the one recorded under field conditions probably due to variations in the enviromental factors and uneven distribution of innoculum in the soil. This was in agreement with the findings of Thakur et al. (2007) who suggested that field screening using trials at hotspot 
and relying on natural infection has not been effective due to variations in environmental factors and uneven distribution of inoculum in the soil. Although for our case, the field screening was effective in the season when the experiment was done.

\section{Conclusion}

The study has identified sorghum genotypes that are tolerant, moderately tolerant and susceptible to covered kernel smut disease in Western Kenya through field and greenhouse screening. All the commercial and farmer varieties were found susceptible to the CKSD. The tolerant varieties included MUK27, T53B, N68, T30B, E117B, MUK157, IS3092 and N4 while the susceptible ones were, Nyadundo 1 and 2, Ochuti, Jowi and C26.The observed large variation in incidence and severity indicates possibility of managing the disease through selection and breeding for resistant varieties. We recommend further breeding for genetic improvement of sorghum using the identified resistant lines.

\section{Acknowledgements}

We wish to acknowledge the McKnight Foundation, Crop Collaborative Research Program for the financial support to sorghum project 'Enhancing livelihoods of smallholder farmers in Western and Eastern Kenya through agro-ecological intensification with sorghum-based interventions' which facilitated this study. I also wish to acknowledge Dr. Makumba Billy of Moi University for identifying the fungus.

\section{References}

Adene, T., \& Guatam, R. D. (2000). Validation of famer's technical knowledge in the utilization of natural products for pest management in Ethiopia and India. Paper presented to International Symposium on Utilization of Natural Products in Developing Countries: Trends and Needs, Natural Products Institute, University of the West Indies, July 9-14, 2000, Mona, Jamaica.

Ashok, S., Patil, B., \& Jamadar, M. (2011). A Review of Sorghum (Sorghum bicolor (L.) Moench) (pp. 70-130). University of Agricultural Sciences, New Delhi, India.

CFC and ICRISAT. (2004). Alternative uses of sorghum and pearl millet in Asia: Proceedings of the Expert Meeting. International Crops Research Institute for the Semi-Arid Tropics on July 1-4, 2003.

Chaube, H. S., \& Punder, V. S. (2005). Crop diseases and their management (pp. 23-56). Oxford and IBH Publishing Co. PVT Ltd.

Esele, J. (2013). Foliar and head diseases of sorghum. Africa Crop Science Journal, 3, 185-189.

FAO. (2012). Global Cereal Crop Rankings. FAO, Rome. Retrieved from http://www.fao.org//faostat

Frederisken, A., \& Odvody, G. (2000). Covered kernel smut. In A. Frederisken \& G. Odvody (Eds.), Compendium of Sorghum Diseases (pp. 21-24). Minnesota, USA: American Physiopathology Society Press.

Gomez, K., \& Gomez, A. (1984). Statistical Procedures for Agricultural Research (pp. 17-704). John Wiley and Sons.

Gono, T., Mangombe, N., \& Mtisi, E. (2004). Sorghum/pearl millet covered kernel smut disease incidence. Report on on-farm sorghum/pearl millet trials monitoring tour in Zimbabwe (pp. 185-188).

Gwary, D. M., Obida, A., \& Gwary, S. D. (2007). Management of sorghum smuts and anthracnose using cultivar selection and seed dressing fungicide in Maiduguri, Nigeria. International Journal of Agriculture and Biology, 9(2), 324-328.

Hayden, N. J. (2002). Promotion of sustainable control of covered kernel smut of sorghum through broadening the cropping base R7518 (ZA0361) (p. 82, Final Technical Report). University of Greenwich, Chatham Maritime, Chatham, Kent.

Howard, F., Gent, H., \& Brown, W. (2005). Identification and life cycle of Sorghum Covered Kernel Smut. Global Research Journal of Agriculture, 34(20), 1-9.

IPM (Integrated Pest Management). (2008). Reports on plant diseases (RPD). Global Advanced Research of Agricultural Science, 408(7), 1-6.

Jere, J. (2004). Identification of fungal pathogens in farm saved and certified seeds of sorghum and evaluation of the incidence and severity of seed borne and non-seed borne diseases in the field. Zimbabwe.

Kutama, A. S., Umar, S., Blanta, U. B., \& Tijjani, A. (2013). Methods for the screening of sorghum germplasms against sorghum head and loose smuts in Nigeria. Global Advanced Research Journal of Agricultural Science, 2(9), 246-251. 
Marley, S., Gupta, S., \& Aba, D. (2002). Assessment of Sorghum genotypes for resistance to foliar Anthracnose (Colletotrichum graminicola) under field conditions. Samara Journal of Agriculture, 18(4), 17-24.

Mtisi, E., \& McLaren, N. W. (2003). Diseases of Sorghum and Pearl Millet in some Southern African Countries. Sorghum and Millet Diseases (pp. 400-409). Iowa State Press, USA.

NASS (National Agricultural Statistics Service). (2019). Agricultural Statistics Board. United States Department of Agriculture (USDA), USA.

Nzioki, A., Clafin, L., Bramel, P., \& Ramundo, B. (2000). Inheritance of resistance to Sporosorium sorghi in Sorghum. International Sorghum and Millet Newsletter Journal, 42(25), 47-50.

Okongo, C., Ouma, E., \& Gudu, S. (2019). A survey of sorghum covered kernel smut disease infection in western Kenya. International Journal of Science and Research, 8(2), 1349-1358.

Perez, T. (2002). Classification of Sporisorium sorghi. Journal of Mycology, 8(1), 140-142.

Sisay, A., Abebe, F., \& Wako, K. (2012). Evaluation of three potentials botanicals against sorghum covered kernel smut (Sphacelotheca sorghi) at Bako, Western Oromia Ethiopia. African Journal of Plant Science, 6(8), 226-231. https://doi.org/10.5897/AJPS10.131

Takan, J. P., Akello, B., Esele, P., Manyasa, E. O., Obilana, A. B., Audi, P. O., ... Ajanga, S. (2004). Finger millet blast pathogen diversity and management in East Africa: A summary of project activities and outputs. Newsletter, 45, 66-69.

Tittonell, P., Muriuki, A., Shepherd, K. D., Mugendi, D., Kaizzi, K. C., Okeyo, J., ... Vanlauwe, B. (2010). The diversity of rural livelihoods and their influence on soil fertility in agricultural systems of East Africa-A typology of smallholder farms. Agricultural Systems, 103, 83-97. https://doi.org/10.5897/AJPS10.131

Tonapi, V. A., Tiwan, H. S., Kumar, A., Bhat, B. U., \& Reddy, C. R. (2020). Food-Fodder-Feed-Fuel for a rapidly changing world. Sorghum in the $21^{\text {st }}$ Century.

Wilson, K. (2011). Sorghum ratooning as an approach to manage covered kernel smut and the stem borer Chilo partellus. Global Advanced Research Journals of Agricultural Science, 2(7), 300-361.

\section{Copyrights}

Copyright for this article is retained by the author(s), with first publication rights granted to the journal.

This is an open-access article distributed under the terms and conditions of the Creative Commons Attribution license (http://creativecommons.org/licenses/by/4.0/). 